tions have reduced the risk of exposure to contaminated blood by $50 \%$ or more. However, slightly more than half would like to see more stringent regulations added. According to the respondents, however, Universal Precautions could be improved; nearly half suggested more thorough enforcement.

Awareness of the new Occupational Safety and Health Administration (OSHA) guidelines on bloodborne pathogens was not high. Only half were aware of the guidelines, and $82 \%$ of those thought their hospital was implementing the new procedures.

The overwhelming majority of nurses polled in this survey were experienced. Eight out of ten had more than four years of nursing experience and two-thirds had four or more years of experience in critical care nursing. The nursing specialties included $40 \%$ intensive care unit/critical care unit, $14 \%$ cardiothoracic surgery, $13 \%$ emergency, $6 \%$ general surgery, $5 \%$ pediatrics, and $5 \%$ neuroscience.

Three out of four nurses polled felt that critical care nurses have a higher risk of accidental needlestick than other hospital nurses and $71 \%$ feel that they have a moderate to high personal risk.

\section{Nationwide Screening Program Launched to Identify Individuals Infected With Hepatitis B and C}

Concerned that millions of Americans are infected with hepatitis $\mathrm{B}$ and $\mathrm{C}$-without knowing it-the American Liver Foundation (ALF) announced a nationwide screening campaign in early September to detect these infectious and potentially fatal liver diseases. Beginning this September, free blood tests for hepatitis B and C have been offered to the public at hospitals in 100 citites throughout the United States.

According to the Centers for Disease Control, hepatitis $\mathrm{B}$ and $\mathrm{C}$ are recognized as two of the most underreported and underdiagnosed infectious diseases in this country. Of great concern is that the source of infection is frequently unknown. Each year, approximately 300,000 Americans become acutely infected with heaptitis B and another 170,000 with hepatitis C. Of those, $30 \%$ with hepatitis B and $40 \%$ with hepatitis $\mathrm{C}$ report no identifiable source of infections. Unlike the human immunodeficiency virus (HIV), the hepatitis B virus can survive on countertops and objects such as razors and toothbrushes for several days. Exposure to blood and, in the case of hepatitis B only, sexual contact, account for most of the remaining cases.

Hepatitis B and C represent serious national health threats because they can projgress to chronic hepatitis-a liver disease that can lead to cirrhosis, liver failure, and liver cancer. As many as 24,000 Americans with hepatitis B and 85,000 with hepatitis C develop chronic hepatitis each year.

Among the groups recognized at high risk are people who are intravenous drug abusers, those who have undergone blood transfusion or hemodialysis, and heathcare workers. Also at risk for hepatitis B are the millions of individuals who have had multiple sex partners. Symptoms range from fatigue, nausea, and loss of appetite, to no symptoms at all.

Free, walk-in blood screenings for hepatitis B and $\mathrm{C}$ were provided at hospitals in 40 cities nationwide for four days in September. Hospitals in another 60 cities will offere screenings in 1993.

ALF's hotline (800-223-0179) is staffed between 8:30 A.M. and 5:00 Em. (EDT) to provde callers with information on where screenings are being held, physician referrals, and free hepatitis consumer brochures.

The Hepatitis Education Program is being funded by a grant from Schering Corporation. Laboratory test kits are being provided by Abbott Laboratories. 